\title{
A CONSTITUIÇÃO TEÓRICO-METODOLÓGICA DA BIBLIOTECA ESCOLAR: CONTRIBUIÇÃO DOS GRUPOS DE PESQUISA DO CNPQ NO CAMPO DA CIÊNCIA DA INFORMAÇÃO
}

\author{
DALGIZA ANDRADE OLIVEIRA* \\ ELAINE CRISTINA RODRIGUES ${ }^{*}$
}

\begin{abstract}
RESUMO
O artigo apresenta os resultados de pesquisa realizada sobre a temática da Biblioteca Escolar, sob os aspectos ligados à produção científica. Objetivou esboçar um panorama teórico, constituído a partir da contribuição da área da Ciência da Informação. A pesquisa teve caráter quantitativo, valendo-se de técnicas bibliométricas além de descritivo, tendo sido realizada a partir dos dados levantados no Diretório de Grupos de Pesquisa no Brasil, do CNPq. Os resultados apontam para uma produção científica concentrada em alguns grupos, sendo estes criados nas últimas décadas; demonstra a variação positiva a partir de 2010 , ano de implementação da Lei 12.244, que se caracteriza pela universalização das Bibliotecas Escolares, e elenca outros pontos quanto aos grupos de pesquisa, pesquisadores e a produção científica
\end{abstract}

PALAVRAS-CHAVE: Biblioteca Escolar; Produção Científica; Grupos de Pesquisa; Lei $n^{\circ} 12.244$.

\begin{abstract}
The article presents the results of research conducted on the theme of the School Library under the aspects of scientific production. It aims to draw a sketch of the theoretical overview, made from the contribution of the area of Information Science. The research is quantitative using bibliometric techniques in addition to descriptive data collected in the Research Groups Directory in Brazil, CNPq. The results point to a scientific production concentrated in some groups, which are created in the last decades; demonstrates the positive change from 2010, year of implementation of Law number 12.244, which is characterized by the universalization of School Libraries in Brazil, and lists other points about the research groups, researchers and scientific production.
\end{abstract}

KEYWORDS: School Library; Scientific Production; Research Groups; School Library Law - 12.244.

* Doutora em Ciência da Informação pela Universidade Federal de Minas Gerais.
${ }^{*}$ Bibliotecária da Escola Estadual São Pio X - São Gotardo/ Minas Gerais. 


\section{INTRODUÇÃO}

A Ciência da Informação (Cl), no Brasil, tem se expandido nas últimas duas décadas de maneira progressiva, por meio da criação de novos cursos de Mestrado Acadêmico e Profissional e implantação de mais cursos de Doutorado. Essa expansão, além de numérica, tem possibilitado também a ampliação de sua agenda de pesquisa, aumentando o seu escopo com temáticas necessárias e prementes ${ }^{1}$.

$\mathrm{O}$ enfoque dado às temáticas estudadas nos programas de pesquisa constitui a centralidade de pesquisa através da produção científica produzida por esses. Essa produção é aqui entendida sob as duas óticas colocadas por Correia, Alvarenga e Garcia (2012, p. 232) como,

a primeira é a da prestação de contas do docente para com a sociedade que financia a pesquisa; e a segunda é entendida como a troca de informação entre cientistas, através dos diversos meios de comunicação (formais e informais). Assim, ao realizar pesquisa e comunicar seus resultados, os pesquisadores estão exercendo atividades essenciais para a disseminação do conhecimento.

A partir do estudo da produção científica de uma área, torna-se possível fazer um mapeamento desta, facilitando identificar os temas abordados, analisar o impacto e o crescimento, tendências de estudos, como também a forma de a comunidade científica se organizar e se estruturar. Segundo Marcelo e Hayashi (2013, p. 139), "analisar a produção do conhecimento científico se tornou uma tarefa muito utilizada nas últimas décadas, pois através dela é possível entender, mesmo em meio a tanta informação, como um determinado campo de saber vem se desenvolvendo".

Nessa perspectiva, a implementação da Lei $n^{\circ} 12.244$, que "dispõe sobre a universalização das bibliotecas nas instituições de ensino do País" (BRASIL, 2010), trouxe à superfície a discussão sobre bibliotecas escolares. Temática essa que tem ganhado atenção dos bibliotecários, pesquisadores, bem como da comunidade no entorno da Biblioteconomia e da $\mathrm{Cl}$.

A abordagem da temática da Biblioteca Escolar (BE) nos programas de pesquisa suscita a necessidade de estudos mais aprofundados sobre a produção científica que revelem o percurso já realizado, com o objetivo de servir de aparato para novas

\footnotetext{
${ }^{1}$ Fundação Coordenação de Aperfeiçoamento de Pessoal de Nível Superior, 2014.
} 
investigações e da construção de um arcabouço teóricometodológico que legitime a área. Como apontado por Campello et al. (2013, p. 126), de que se prescinde "necessário, conhecer melhor as pesquisas já realizadas sobre o tema, de forma a estabelecer 0 estado da arte deste corpo de conhecimentos no que diz respeito à produção científica brasileira sobre biblioteca escolar".

Nessa linha de pensamento, o presente artigo deriva de uma pesquisa que analisou as contribuições da $\mathrm{Cl}$ à $\mathrm{BE}$ no Brasil. Dessa forma, apresentam-se alguns resultados que estabelecem a dimensão dos estudos que têm sido realizados na área. $O$ trabalho identificou os grupos de pesquisa cadastrados no Diretório dos Grupos de Pesquisa no Brasil ${ }^{2}$, do Conselho Nacional de Desen-volvimento Científico e Tecnológico ( $\mathrm{CNPq})$, suas respectivas linhas de pesquisa e os pesquisadores a elas vinculados, enunciando os interesses na temática e possibilidade de novos estudos. No estudo, também se mapeou a produção científica desses pesquisadores, revelando como se dá o processo da comunicação científica nesses grupos.

\section{BIBLIOTECA ESCOLAR}

A BE é um dispositivo que se desenvolve em conjunto com as atividades curriculares do ensino regular, proporcionando acesso à comunidade escolar a um acervo organizado, com diversidade de materiais e em vários suportes, para leitura e pesquisa. A BE deve contar com espaço físico adequado, computadores com acesso à internet, como também com a presença de bibliotecário ${ }^{3}$ e apresentação de serviços múltiplos que devem ir muito além da consulta e empréstimo do acervo.

Considerando a abundância de informações na contemporaneidade, a biblioteca tem sido abordada também como um lugar de aprendizagem de competências informacionais, sendo considerada como um "espaço por excelência para promover experiências criativas de uso de informação" (CAMPELLO, 2008, p. 11).

A tarefa de repensar a biblioteca tem sido observada pelos organismos que a defendem e por estudos na área da Biblioteconomia e da Ciência da Informação. Se antes era vista como apenas um espaço de leitura, hoje a pesquisa é apontada como espaço de aprendizagem ao longo da vida. Verifica-se, pois, estudos

${ }^{2}$ Conselho Nacional de Desenvolvimento Científico e Tecnológico, 2014.

${ }^{3}$ Conforme os dispositivos da Lei $n^{\circ}$ 4084/62 e Decreto 56725/65. 
nos mais diversos âmbitos na área, tendo esse princípio de aprendizagem abordado pelos pesquisadores e profissionais. Como ressalta o manifesto para biblioteca escolar da International Federation of Library Associations (IFLA, 2000), a BE "habilita os estudantes para a aprendizagem ao longo da vida e desenvolve a imaginação, preparando-os para viver como cidadãos responsáveis".

O Conselho Federal de Biblioteconomia e os Conselhos Regionais (CFB/CRB, 2008, p. 6), nessa linha de pensamento, afirmam, sobre a natureza da função da BE, que deve ser

um espaço constituído para, uma vez assimilado pelo aluno, professor e demais entes que constituem os atores do ambiente escolar, possibilitar a interação com os processos de conhecimento de modo a contribuir para uma formação satisfatória do indivíduo, favorecendo o aprender a aprender, ou seja, corroborando para a aquisição da habilidade de aprender, saber obter, utilizar e gerar novas informações.

$\mathrm{Na}$ prática, as intenções postas sobre a BE se encontram muito longe de ser realidade. No fim dos anos 1990, a situação na qual se encontravam as Bibliotecas Escolares era tão desoladora quanto a miséria que retratou Silva (1995), em meados do século XX. Em levantamento sobre a situação no estado do Rio de Janeiro, Quinhões (1999) avalia a inexistência de bibliotecas, a deficiência nas instalações, o acervo reduzido, falta de recursos materiais e a pouca ou nenhuma importância dada à Biblioteca pelos professores.

Com a criação do Programa Nacional Biblioteca da Escola (PNBE), que é desenvolvido desde 1997, as escolas públicas passaram a receber acervo bibliográfico de obras de literatura, referência, pesquisa e materiais relativos ao currículo, de acordo com a ideia de "democratização do acesso às fontes de informação, ao fomento à leitura e à formação de alunos e professores leitores e ao apoio à atualização e ao desenvolvimento profissional do professor" (FUNDO NACIONAL DE DESENVOLVIMENTO DA EDUCAÇÃO, 2012).

Contudo, a falta de espaço físico, mobiliários, informatização e profissional qualificado ainda é um peso para o uso efetivo da BE e aproveitamento das suas potencialidades para o ensino. Freitas (2013) destaca a falta de espaço e identidade, apontando para o fato de que a $B E$ vem sendo denominada de muitas coisas, menos de biblioteca escolar. $\mathrm{E}$ assinala que problemas quanto à educação se relacionam com a infraestrutura e ao organograma das escolas públicas, que afetam na falta de $B E$ e de profissionais bibliotecários habilitados, limitando a formação integral dos alunos (FREITAS, 2013). 
Alguns autores abordam as condições das BE no Brasil (MAROTO, 2012; SERAFINI et al, 2011; FREITAS, 2013; QUINHÕES, 1999, entre outros). Partindo de diversas realidades, enfatizam as dificuldades que as BE enfrentam de falta de espaço adequado para sua acomodação; a indisponibilidade de recursos necessários quando a escola a possui, evitando que cumpra seu papel social e educativo; o descaso de governos; a inexistência de políticas públicas e privadas; desconhecimento e descumprimento de legislação (quando existe); e falta de profissionais habilitados.

Em diagnóstico do PNBE no Brasil, em 2005, 196 escolas de Ensino Fundamental, localizadas em 19 municípios de oito estados, serviram de amostra estatística para a pesquisa desenvolvida pela Associação Latino-Americana de Pesquisa e Ação Cultural (ALPAC). Sobre o quadro das BE, foi evidenciada, entre tantos outros pontos, a deficiência no espaço das bibliotecas, que, em sua maioria, são salas ou locais nada atrativos, espaço físico para depósito de livros, acúmulo de livros didáticos e falta de bibliotecário com formação. A respeito do material bibliográfico, observou-se o sentido de livro como parte do patrimônio, o que impede que o aluno se aproprie do mesmo; falta de sentimento de pertencimento, ao ambiente e ao livro; ausência de política de formação de leitores; professores que não sabem utilizar os acervos e diferenciá-los; policiamento aos alunos, limitando-os a leituras que sigam o roteiro escolar (BRASIL, 2008).

Tal quadro observado nas $B E$ derivou na insatisfação e em pressões por parte dos órgãos representantes de Biblioteconomia no Brasil para que houvesse maior interesse das autoridades, culminando na Lei $n^{\circ} 12.244$ de 24 de maio de 2010, que representou "de forma significativa os anseios de uma camada da sociedade que requer melhorias" (ALBUQUERQUE; TEDESQUI, 2014 , p. 124). Desse modo, de acordo com a lei, "os sistemas de ensino do País deverão desenvolver esforços progressivos para que a universalização das bibliotecas escolares, nos termos previstos nesta Lei, seja efetivada num prazo máximo de dez anos, respeitada a profissão de Bibliotecário" (BRASIL, 2010).

Embora seja um ganho para a BE, estudos que abordaram os aspectos da Lei $n^{\circ} 12.244$ indicaram obstáculos para que se torne efetiva, tais como o número de bibliotecas que deveriam ser abertas e profissionais bibliotecários que precisariam ser formados nesse tempo são os entraves mais impactantes, entre outros apontados por Freitas (2013) e omitidos pela lei, que não indica sobre os meios necessários à implantação das $B E$ bem como dos recursos mínimos necessários de infraestrutura, financeiros, etc. para a sua concretização. 


\section{PERCURSO METODOLÓGICO}

Acerca da metodologia de pesquisa, González de Gómez (2000) entende que os métodos, quantitativos, qualitativos, comparativos, bem como as técnicas de coleta e análise da informação, indicam o direcionamento e tipo das atividades de pesquisa de maneira secundária, estando já baseados num domínio epistemológico e político que recebe e dá legitimidade às condições de produção do objeto da investigação. Assim, prossegue a autora, uma metodologia de pesquisa teria, como primeira atividade a se realizar, a tematização dessas condições de produção do objeto de conhecimento (GONZÁLES DE GOMEZ, 2000).

Dessa forma, a definição da metodologia se torna fundamental para a pesquisa, pois coordena a direção e a forma como o objeto de pesquisa será tratado, definindo os meios para a obtenção dos resultados.

Nesse sentido, inicialmente foram definidas as categorias de análise, sendo estas os grupos de pesquisa, as linhas de pesquisa, os pesquisadores e a produção científica.

Na sequência, realizou-se levantamento de dados no Diretório de Grupos de Pesquisa no Brasil (DGP), do CNPq. Nesse quesito, identificaram-se, a contar da temática proposta, os grupos de pesquisa, linhas de pesquisa e seus respectivos pesquisadores. Foram considerados os grupos com o foco de suas pesquisas em $\mathrm{BE}$, como também os grupos que contemplassem essa temática em pelo menos uma de suas linhas de pesquisa. A pesquisa no entorno dos grupos no DGP no Brasil foi realizada a partir do termo Biblioteca Escolar, considerando o nome, objetivo e palavras-chaves dos grupos e linhas de pesquisa.

Identificados os pesquisadores, o levantamento quanto à formação, atuação acadêmica e produção científica, foi realizado, na Plataforma Lattes do CNPq, um exame de todo currículo de cada pesquisador. Quanto à produção científica, o termo de busca considerado foi Biblioteca Escolar, assim como se valeu do mesmo expediente nos grupos de pesquisa. O limite temporal não foi estabelecido, sendo considerada toda a produção do pesquisador. Para a estruturação da análise valeu-se dos recursos bibliométricos ${ }^{4}$.

\footnotetext{
${ }^{4}$ Para Sancho (1990), com os indicadores bibliométricos pode-se determinar, o crescimento de qualquer campo da ciência, segundo a variação cronológica do número de trabalhos publicados; a produtividade dos autores ou instituições,
} 


\section{RESULTADOS E DISCUSSÕES}

Tendo em vista a incipiência de estudos sobre BE no Brasil, há que se considerar que os resultados ficaram adequados ao que se esperava. Vale destacar, contudo, que a emergência de reflexões acerca da temática coloca para a Biblioteconomia e para a $\mathrm{Cl}$ um desafio: tornar essa temática entre as prioritárias na agenda de pesquisa da área!

\subsection{Grupos de pesquisa}

Foram recuperados oito grupos de pesquisa no campo da $\mathrm{Cl}$, distribuídos em sete universidades, criados entre os anos de 1998 e 2013.

\begin{tabular}{|c|c|c|c|c|c|c|}
\hline & $\begin{array}{l}\text { Grupo de } \\
\text { Pesquisa }\end{array}$ & $\begin{array}{l}\text { Linhas de } \\
\text { Pesquisas }\end{array}$ & Instituição & Estado & Ano & Pesquisadores \\
\hline GP1 & $\begin{array}{c}\text { Estudos } \\
\text { convergentes em } \\
\text { Ciência da } \\
\text { Informação }\end{array}$ & $\begin{array}{l}\text { Pesquisa, Ação e } \\
\text { Intervenção em } \\
\text { Biblioteconomia e } \\
\text { Ciência da } \\
\text { Informação }\end{array}$ & UFSCAR & SP & 2012 & 1 \\
\hline GP2 & $\begin{array}{l}\text { Fundamentos } \\
\text { teóricos da } \\
\text { Informação }\end{array}$ & $\begin{array}{c}\text { Teorias da } \\
\text { Comunicação e das } \\
\text { Mediações }\end{array}$ & UNESP & SP & 2010 & 2 \\
\hline GP3 & $\begin{array}{l}\text { GPInfo - Grupo } \\
\text { de Pesquisa em } \\
\text { Informação }\end{array}$ & $\begin{array}{l}\text { Informação, } \\
\text { Memória e } \\
\text { Sociedade }\end{array}$ & UDESC & SC & 1998 & 2 \\
\hline GP4 & $\begin{array}{c}\text { Grupo de estudos } \\
\text { em Biblioteca } \\
\text { Escolar }\end{array}$ & $\begin{array}{l}\text { Informação, Cultura } \\
\text { e Sociedade }\end{array}$ & UFMG & MG & 1998 & 8 \\
\hline & Leitura, Biblioteca & $\begin{array}{l}\text { Biblioteca Escolar } \\
\text { e Processos de } \\
\text { Leitura }\end{array}$ & & & & \\
\hline GP5 & $\begin{array}{l}\text { Escolar e } \\
\text { Cidadania }\end{array}$ & $\begin{array}{c}\text { Informação e Ação } \\
\text { Cultural } \\
\text { Leitura e } \\
\text { Bibliotecas Digitais }\end{array}$ & UFAL & $\mathrm{AL}$ & 2011 & 2 \\
\hline
\end{tabular}

medida pelo número de seus trabalhos; colaboração entre os pesquisadores ou instituições; impacto ou visibilidade das publicações dentro da comunidade científica internacional, medido pelo número de citações que recebem por parte dos trabalhos posteriores e a dispersão das publicações científicas entre as diversas fontes, etc. 


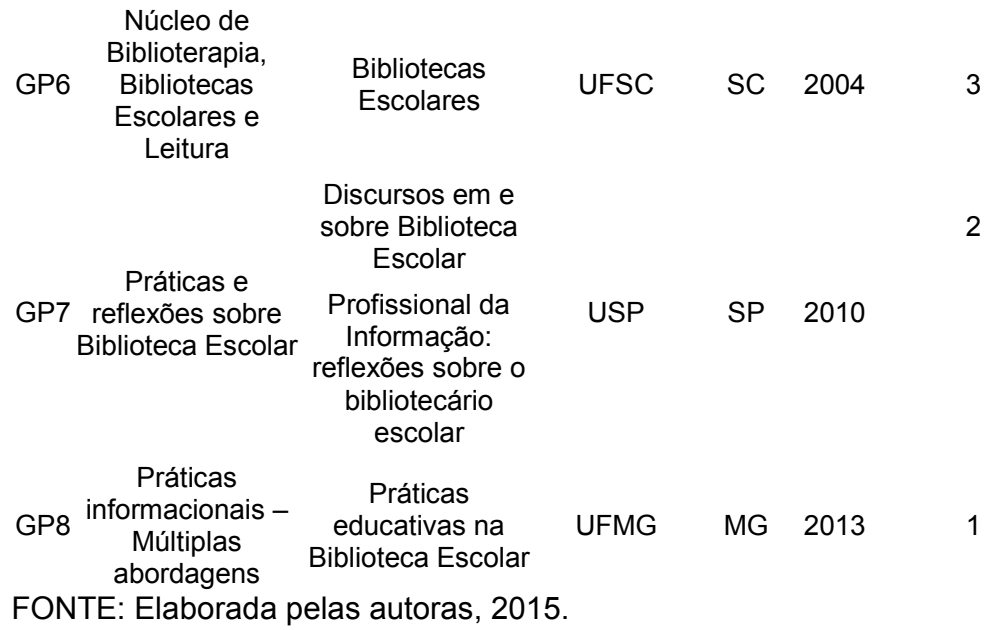

Em consideração aos dados levantados, os grupos de pesquisa identificados localizam-se predominantemente em universidades públicas da região sudeste. Nesse contexto, observa-se que nas demais regiões ainda há carência da discussão da temática.

Por outro lado, quanto ao ano de formação dos grupos de pesquisa, dos oito grupos elencados, três têm mais de 10 anos de criação, enquanto cinco tiveram seu surgimento a partir de 2010. Importante frisar que no ano de 2010 foi estabelecida a Lei $\mathrm{n}^{\circ} 12.244$.

Dessa forma, ainda que a discussão sobre $B E$ seja incipiente em parte da agenda das instituições de pesquisa em todo o Brasil, mesmo assim, é possível afirmar que a importância dada ao tema recebeu novos olhares com essa legislação. Tal constatação depreende da aprovação da referida lei bem como da abertura e, ao mesmo tempo, pressão que a mesma tem promovido junto a instituições de ensino, tanto públicas como privadas, responsáveis pelas Bibliotecas Escolares no país.

\subsection{Linhas de pesquisa}

Dentro dos oito grupos identificados, as linhas de pesquisa que abordam a temática da BE totalizam-se em 11 e contam com 24 pesquisadores. 
Na página de cada linha de pesquisa no DGP, são atribuídas palavras-chave, que puderam ser visualizadas conforme figura abaixo:

FIGURA 1 - Nuvem de palavras-chave relacionadas às linhas de pesquisa

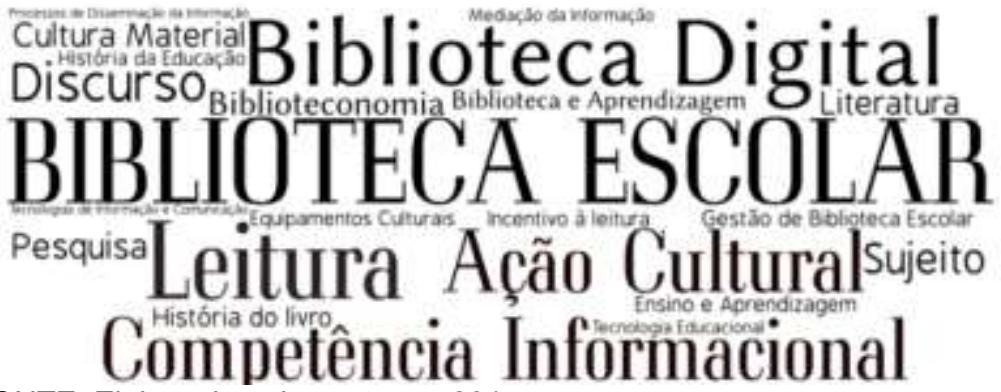

FONTE: Elaborada pelas autoras, 2015.

O quadro 2 mostra a ocorrência das palavras-chave das linhas de pesquisa:

QUADRO 2 - Ocorrências das palavras-chave das linhas de pesquisa

\begin{tabular}{|l|c|}
\hline Biblioteca Escolar & 8 \\
\hline Leitura & 4 \\
\hline Ação Cultural; Competência Informacional; Práticas Educativas & 2 \\
\hline Atividade Cultural; Biblioteca; Biblioteca Digital; Biblioteca e & \\
Aprendizagem; Biblioteca Escolar Digital; Biblioteconomia; Ciência & \\
da Informação; Cultura Material; Discurso; Ensino Básico; Ensino & \\
e Aprendizagem; Equipamentos Culturais; Escrita; Formação; & \\
Gestão de Biblioteca Escolar; História da Educação; História do & \multirow{2}{*}{$\begin{array}{l}\text { livro; Impressos; Incentivo à Leitura; Letramento Informacional; } \\
\text { Literatura; Mediação; Mediação Cultural; Mediação da }\end{array}$} \\
Informação; Pesquisa; Processos de Disseminação da & \\
Informação; Profissional da Informação; Sujeito; Tecnologia & \\
Educacional; Tecnologias de Informação e Comunicação & \\
\hline
\end{tabular}

FONTE: Elaborada pelas autoras, 2015.

A BE aparece em oito, entre 11 linhas de pesquisa. Ainda que não ocorra nos nomes que determinam as linhas, o termo Biblioteca Escolar se encontra nos registros da linha ou do grupo de pesquisa. O que se deve salientar é que além de ser a temática mais citada, esta é abordada juntamente com outras transversais, como leitura, competência informacional, práticas educativas, gestão de biblioteca escolar, entre outros. 
O levantamento das palavras-chave das linhas de pesquisa demonstra como a temática da BE tem sua imagem intrinsecamente ligada à leitura - o termo aparece em quatro linhas de pesquisa. Mas demonstra também os direcionamentos dos estudos na área, como a BE vem sendo abordada como espaço de práticas de ação cultural. $E$ vai além, tendo tido como lugar fundamental para aprendizagem de competências informacionais e entendida não apenas como equipamento que apoia a formação de leitores, mas que tem um papel educativo diante do sistema de ensino que deve ser tomado para si, reelaborando e reestruturando o panorama do seu papel.

\subsection{Pesquisadores}

Foram enumerados 21 pesquisadores, ligados aos grupos de pesquisa, contudo, um único pesquisador faz parte do GP4 e GP8, obtendo assim a totalização de 20 pesquisadores individualmente.

O quadro 3 refere-se à formação e titulação acadêmica dos pesquisadores listados:

QUADRO 3 - Formação dos pesquisadores

\begin{tabular}{|c|c|c|c|c|c|}
\hline Graduação & & Mestrado & & Doutorado & \\
\hline Biblioteconomia & 9 & Bibliotecas Públicas & 1 & $\begin{array}{c}\text { Ciência da } \\
\text { Informação }\end{array}$ & 9 \\
\hline $\begin{array}{c}\text { Biblioteconomia } \\
\text { e Documentação }\end{array}$ & 3 & Biblioteconomia & 1 & Educação & 1 \\
\hline $\begin{array}{c}\text { Ciência da } \\
\text { Computação }\end{array}$ & 1 & $\begin{array}{c}\text { Ciência da } \\
\text { Computação }\end{array}$ & 1 & $\begin{array}{c}\text { Estudos } \\
\text { Literários }\end{array}$ & 1 \\
\hline Ciências Sociais & 2 & $\begin{array}{c}\text { Ciência da } \\
\text { Informação }\end{array}$ & 9 & Linguística & 1 \\
\hline $\begin{array}{c}\text { Comunicação } \\
\text { Social }\end{array}$ & 1 & $\begin{array}{c}\text { Ciência da } \\
\text { Informação e } \\
\text { Documentação }\end{array}$ & 1 & Literatura & 1 \\
\hline Letras & 1 & $\begin{array}{c}\text { Ciências Sociais } \\
\text { Comunicação } \\
\text { Social }\end{array}$ & 1 & Psicologia & 1 \\
\hline Não informa & 3 & $\begin{array}{c}\text { Educação } \\
\text { Política }\end{array}$ & 1 \\
\hline & & Sociologia Política & 1 & & \\
\hline & & Não informa & 1 & & \\
\hline
\end{tabular}

FONTE: Elaborada pelas autoras, 2015. 
Os pesquisadores que possuem graduação em Biblioteconomia e Biblioteconomia e Documentação totalizam-se em 12 entre os 20; pesquisadores com a titulação de Mestrado em Cl, $\mathrm{Cl}$ e Documentação, Biblioteconomia e Bibliotecas Públicas totalizam-se em 12, em 19; e pesquisadores com a titulação de Doutorado em $\mathrm{Cl}$ somaram nove em 15.

Observa-se que a temática $\mathrm{BE}$ tem atraído também profissionais de outras áreas. Esse interesse contribui para a formação de equipes interdisciplinares que podem contribuir com olhares diversificados e abordagens variadas. Tal constatação pode ser observada na variedade dos termos encontrados entre as palavras-chave das linhas de pesquisa. Para Le Coadic (2004, p. 22), "interdisciplinaridade traduz-se por uma nova colaboração entre diversas disciplinas, que leva a interações, isto é, uma certa reciprocidade nas trocas, de modo que haja, em suma, enriquecimento mútuo".

Quanto à formação dos docentes, constata-se que cinco pesquisadores não possuem doutorado e apenas um não possui mestrado.

Em observação à docência, foi constatado que, entre os pesquisadores, 15 ministram aulas apenas na graduação, destes, cinco também ministram aulas na pós-graduação, e os cinco demais não ministram aulas. Esse panorama demonstra a graduação como espaço mais amplo e aberto a discussões diversas e, em contrapartida, a pós-graduação ainda é um espaço que não contempla de maneira satisfatória a temática da BE.

\subsection{Produção científica}

Foi levantada a produção científica de cada pesquisador, na plataforma Lattes, identificado no período de 1981 a 2014. Encontraram-se apenas duas produções escritas em espanhol e cinco em inglês, destacando o esforço para a discussão da temática em âmbito nacional. É necessário enfatizar que, devido a essas publicações terem sido identificadas no Currículo Lattes de cada pesquisador, há que se considerar a possibilidade de desatualização destes.

Abaixo (Gráfico 1), as tipologias encontradas entre as 128 referências bibliográficas, identificando a autoria de cada uma. 
GRÁFICO 1 - Tipologia das publicações e autoria

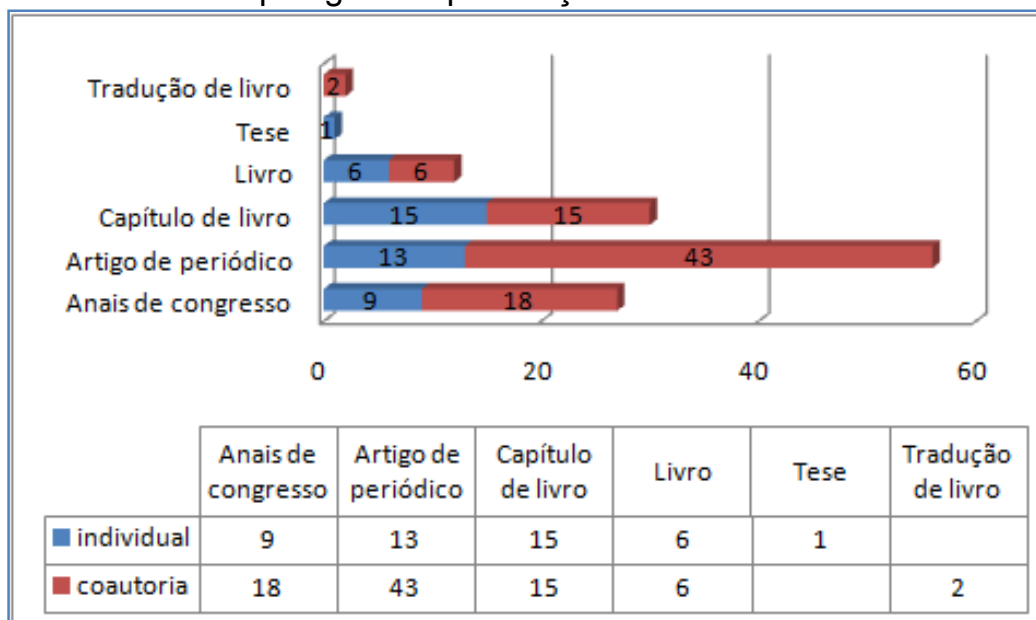

FONTE: Elaborado pelas autoras, 2015.

Como pode ser observado, as publicações dos pesquisadores que tratam da $\mathrm{BE}$, em sua grande maioria, são artigos de periódicos, o que os colocam como meio mais utilizado e, consequentemente, ressalta o periódico científico como o canal mais importante na comunicação dos pesquisadores, atestando sua importância para a comunicação científica. Vale lembrar que, além de divulgação dos resultados de pesquisa, o periódico científico favorece a comunicação formal dos resultados da pesquisa original para a comunidade científica e demais interessados, preservação do conhecimento registrado, estabelecimento da propriedade intelectual e manutenção do padrão da qualidade na ciência (MUELLER, 2000, p. 76).

$\mathrm{Na}$ sequência dos tipos de publicação mais utilizados estão os anais de congresso, que representam canal de comunicação rápida. Os anais vêm seguidos pelos capítulos de livros. Por fim, vem o livro, a tradução e a tese. A recuperação de apenas uma tese na área leva-se a pensar sobre a quase ausente e bem baixa produção em nível de pós-graduação dos pesquisadores, da ausência de estudos sobre BE com o aprofundamento característico da pesquisa em pós-graduação.

Foram recuperadas 44 publicações em autoria individual e 84 em cooperação com os pares. Dessas 84 publicações, nove com pesquisadores exclusivamente do próprio grupo de pesquisa, 60 com pesquisadores fora do grupo ao qual pertencem e 15 publicações com ambos. 


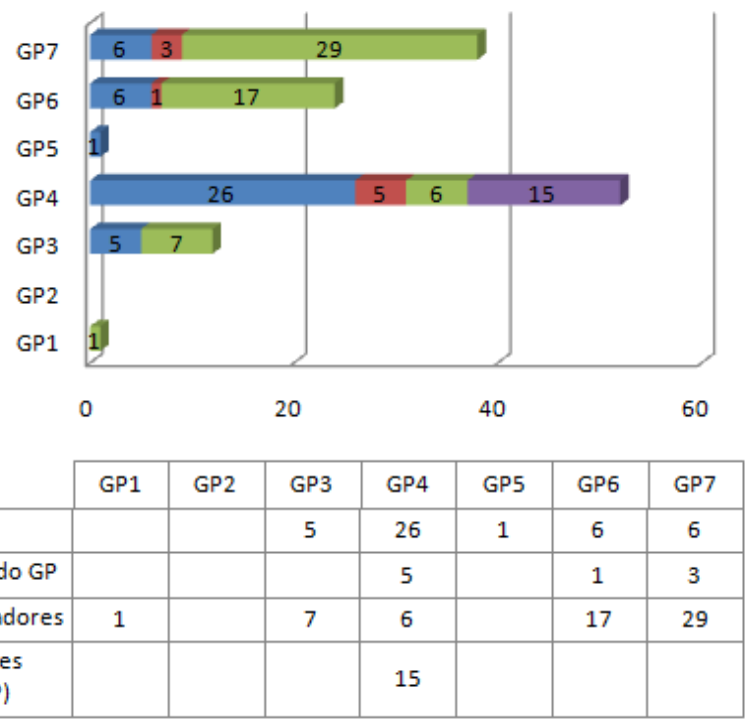

FONTE: Elaborado pelas autoras, 2015.

O estudo demonstrou que os pesquisadores publicam em maior número em coautoria e esta é mais bem articulada com outros pesquisadores, que não aqueles que fazem parte do mesmo grupo de pesquisa, representados principalmente por orientandos.

Elenca-se a publicação colaborativa entre os pares como a opção mais utilizada entre os pesquisadores. Essa preferência indica para a formação de redes sociais que cooperam entre si em torno de um determinado tema, no caso a BE, contribuindo para a pesquisa e seu desenvolvimento.

\subsection{Projetos de Pesquisas e Extensão}

Além das produções já descritas, foram levantados os projetos de pesquisa e extensão. De acordo com o Gráfico 3, foram listados 19 projetos de pesquisa e quatro projetos de extensão, no período de 2004 a 2014, relacionados com a temática. 
GRÁFICO 3 - Projetos por Grupos de Pesquisa

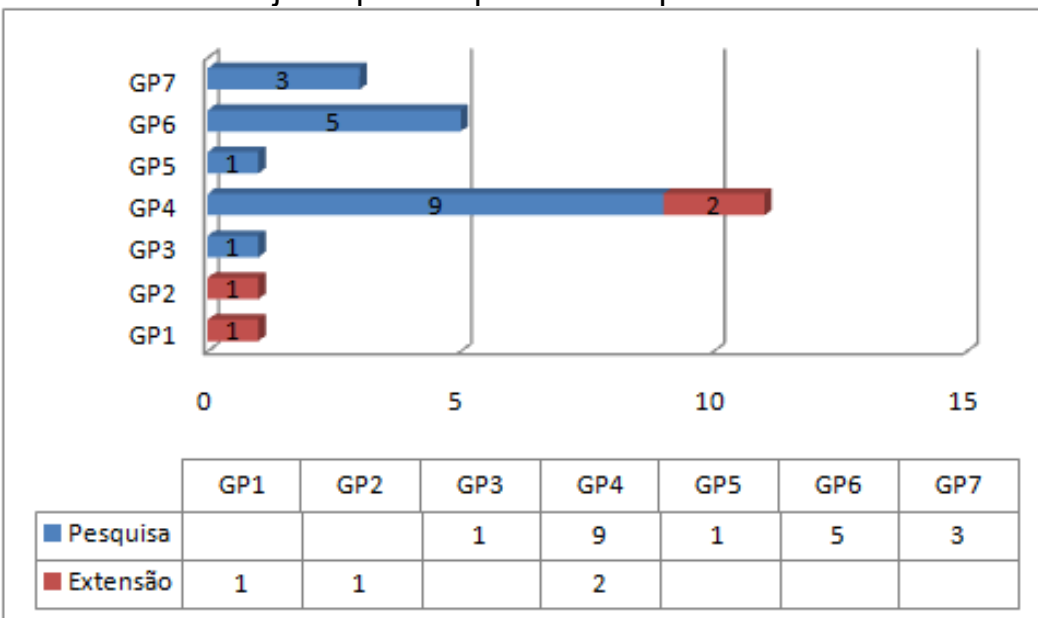

FONTE: Elaborado pelas autoras, 2015.

O quantitativo de projetos elencados demonstra o interesse na $B E$ e como de fato vêm se desenvolvendo as pesquisas, agregando valor ao tema e aprofundando as abordagens.

\section{CONSIDERAÇÕES FINAIS}

A pesquisa apresentou um panorama dos Grupos de Pesquisa nos quais os respectivos pesquisadores são oriundos não apenas da Biblioteconomia e $\mathrm{Cl}$, mas de áreas bem diversas, que refletem na variedade quanto aos aspectos de abordagem da temática, sendo observado esse ponto nos termos que representam as linhas de pesquisa. Isso indica que as pesquisas sobre BE se encontram em âmbitos diversos que podem refletir positivamente no desenvolvimento e abrangência desta temática.

Foi observado na pesquisa que a comunicação científica na área se estabelece principalmente em artigos de periódicos, importante meio de comunicação científica, garantia, entre outros pontos, de legitimidade através da avaliação dos pares. Os anais de congresso são também meios frequentes, demonstrando que o debate sobre a temática está presente em eventos na área da $\mathrm{Cl}$.

Ressalta-se que a produção científica levantada nesta pesquisa é realizada, principalmente, em coautoria, evidenciando-se assim a pesquisa colaborativa que acontece entre os pesquisadores 
dos grupos, mas em maior número com pesquisadores que não pertencem a grupos de pesquisa. A pesquisa colaborativa deve ser estimulada, tendo em vista as potencialidades que essa prática pode trazer em benefício das pesquisas sobre Biblioteca Escolar, como evidência e maior visibilidade ao tema e ampliação das perspectivas de pesquisa devido ao olhar diversificado sobre o mesmo tema. Assim, a pesquisa colaborativa não deve se reduzir aos grupos de pesquisa, mas deve se ampliar através da colaboração entre pesquisadores de instituições diversas.

Sobre as instituições que ocorrem nos Grupos de Pesquisa, em resultados alcançados, observa-se que as pesquisas na área de $\mathrm{Cl}$ sobre $\mathrm{BE}$ se reduzem a algumas instituições. Entende-se como necessária a recorrência a outras áreas transversais como, por exemplo, a educação. Contudo, há que se considerar que, além de o tema ser incipiente nas agendas de pesquisa, há ainda fatores outros que estão além da vontade, necessidade e possibilidades dos pesquisadores.

A pesquisa demonstrou que os Grupos de Pesquisa com abordagem na temática se concentram em instituições públicas, sendo a maioria da região Sudeste. Depreende-se, desse ponto, que a pesquisa e a reflexão no que se refere à $B E$ seja difundida e estimulada nas demais regiões, em que pese todas as dificuldades e limitações, sobretudo, com estabelecimento da Lei $n^{0} 12.244$.

Com a implementação da referida Lei, observa-se, neste estudo, maior evidência à temática, sendo que o surgimento de grupos de pesquisas aumenta nesse período de implementação. Mas há ainda que se considerar a produção científica desses grupos e refletir, uma vez que há uma legislação com pretensão de universalizar as bibliotecas escolares do país. Faz-se necessário mais aportes teóricos para potencializar a prática e servir de base para a discussão e implementação de bibliotecas nas escolas. Sabe-se que a $\mathrm{BE}$ se orienta em acordo com as necessidades específicas do contexto em que ela se insere, o que reforça o interesse de a temática ser trazida para as agendas de pesquisa, dada a importância que a instituição BE tem para o ensino e aprendizado.

\section{REFERÊNCIAS}

ALBUQUERQUE, A. C.; TEDESQUI, C. A. Competências profissionais do bibliotecário escolar: reflexões a partir da Lei 12.244/10. Inf. Prof., Londrina, v. 3 , n. 1/2, p. 115-146, jan./dez. 2014. Disponível em:

$<$ http://www.uel.br/revistas/uel/index.php/infoprof/article/view/20519/>. Acesso em: 25 mar. 2015. 
BRASIL. Decreto $n^{\circ} 56.725$, de 16/08/1965. Regulamenta a Lei no 4.084, de 30 de junho de 1962, que dispõe sobre o exercício da profissão de Bibliotecário. Diário Oficial da União, Poder Executivo, Brasília, DF. Disponível em: < http://www.cfb.org.br/institucional.php?codigo=7>. Acesso em: 15 mar. 2015.

Lei $n^{\circ} 4.084$, de 30/06/1962. Dispõe sobre a profissão de bibliotecário e regula seu exercício. Diário Oficial da União, Poder Executivo, Brasília, DF. Disponível em:

<http://www.cfb.org.br/UserFiles/File/Legislacao/Lei4084-30junho1962.pdf>. Acesso em: 15 mar. 2015.

. Lei $n^{\circ} 12.244$, de 24/05/2010. Dispõe sobre a universalização das bibliotecas nas instituições de ensino do País. Diário Oficial da União, Poder Executivo, Brasília, DF, 25/05/2010. Seção 1, p. 3. Disponível em: $<$ http://www.jusbrasil.com.br/diarios/5259000/pg-3-secao-1-diario-oficial-dauniao-dou-de-25-05-2010>. Acesso em: 15 mar. 2015.

Ministério da Educação. Programa Nacional Biblioteca da Escola (PNBE): leitura e bibliotecas nas escolas públicas brasileiras. Brasília: MEC, 2008. Disponível em:

$<$ http://portal.mec.gov.br/seb/arquivos/pdf/Avalmat/livro mec final baixa.pdf >. Acesso em: 20 mai. 2015.

CAMPELLO, B. et al. Pesquisas sobre biblioteca escolar no Brasil: o estado da arte. Encontros Bibli: revista eletrônica de biblioteconomia e ciência da informação, Florianópolis, v. 18, n. 37, p. 123-156, ago. 2013. Disponível em: $\quad \quad$ https://periodicos.ufsc.br/index.php/eb/article/view/15182924.2013v18n37p123>. Acesso em: 04 mar. 2015.

CAMPELLO, B. A competência informacional na educação para o século XXI. In: CAMPELLO, B. et al. A biblioteca escolar: temas para uma prática pedagógica. 2. ed. Belo Horizonte, 2008. p. 9-11.

CONSELHO NACIONAL DE DESENVOLVIMENTO CIENTÍFICO E TECNOLÓGICO. Diretório dos Grupos de Pesquisa no Brasil: o que é. 2014. Disponível em: http://lattes.cnpq.br/web/dgp/o-que-e/>. Acesso em: 16 maio 2015.

CORREIA, A. E. G. C.; ALVARENGA, L.; GARCIA, J. C. R. Produção científica: reflexos da avaliação nos programas de pós-graduação em física. Em Questão: Revista da Faculdade de Biblioteconomia e Comunicação da UFRGS, Porto Alegre, v. 18, n. 1, p. 231-247, 2012. Disponível em: <http://seer.ufrgs.br/index.php/EmQuestao/article/view/33370/23784>.

Acesso em: 04 mar. 2015.

FREITAS, B. C. Ambiente de Informação: desafios na implantação de bibliotecas escolares em escolas estaduais de ensino fundamental e médio de Ribeirão Preto. In: CONGRESSO BRASILEIRO DE BIBLIOTECONOMIA, DOCUMENTO E CIÊNCIA DA INFORMAÇÃO, 25, 2013, Florianópolis. Anais... Florianópolis: CBBD, 2013. Disponível em: <http://portal.febab.org.br/anais/issue/view/4/showToc>. Acesso em: 21 
maio 2015.

FUNDAÇÃO COORDENAÇÃO DE APERFEIÇOAMENTO DE PESSOAL DE NÍVEL SUPERIOR. Documentos de área. Brasília: CAPES, 2014. Disponível em: <http://www.capes.gov.br/avaliacao/instrumentos-deapoio/documentos-de-area>. Acesso em: 16 maio 2015.

FUNDO NACIONAL DE DESENVOLVIMENTO DA EDUCAÇÃO. PNBE: apresentação. Site de internet. Brasília: FNDE, 2012. Disponível em: $<$ http://www.fnde.gov.br/programas/biblioteca-da-escola/biblioteca-daescola-apresentacao >. Acesso em: 05 jun. 2015.

GONZÁLEZ DE GÓMEZ, M. N. Metodologia de pesquisa no campo da Ciência da Informação. DataGramaZero - Revista de Ciência da Informação, Rio de Janeiro, v. 1, n. 6, 2000. Disponível em: <http://www.dgz.org.br/dez00/Art 03.htm>. Acesso em 04 mar. 2015.

IFLA. Manifesto IFLA/UNESCO para biblioteca escolar. Tradução Neusa Dias Macedo. São Paulo: IFLA, 2000. Disponível em: $<$ http://archive.ifla.org/VII/s11/pubs/portuguese-brazil.pdf>. Acesso em: 22 mar. 2015.

LE COADIC, Y. A ciência da informação. Brasília: Briquet de Lemos/Livros, 2004.

MARCELO, J. F.; HAYASHI, M. C. P. I. Estudo bibliométrico sobre a produção científica da área da sociologia da ciência. Informação \& Informação, Londrina, v. 18, n. 3, p. 138-153, set. 2013. Disponível em: <http://www.uel.br/revistas/uel/index.php/informacao/article/view/8413>.

Acesso em: 04 mar. 2015.

MAROTO, L. H. Biblioteca escolar, eis a questão! Do espaço do castigo ao centro do fazer educativo. 2. ed. Belo Horizonte: Autêntica, 2012.

MUELLER, S. P. M. O periódico científico. In: CAMPELLO, B. S.; VALADARES, B.; KREMER, J. M. (Org.). Fontes de informação para pesquisadores e profissionais. Belo Horizonte: UFMG, 2000. p. 73-96.

QUINHÕES, M. E. T. Biblioteca escolar: sua importância e seu espaço no sistema educacional do Estado do Rio de Janeiro. In: VIANNA, M. M.; CAMPELLO, B.; MOURA, V. H. V. Biblioteca escolar: espaço de ação pedagógica. Belo Horizonte: EB/UFMG, 1999. p. 178-182.

$\mathrm{SANCHO}, \mathrm{R}$. Indicadores bibliometricos utilizados en la evaluación de la ciência y la tecnologia: revision bibliográfica. Revista Española de Documentación Científica, Madrid, v. 13, n. 3-4, p. 842-65, 1990.

SERAFINI, L. T. et al. Novas tendências para as bibliotecas escolares brasileiras: fórum gaúcho pela melhoria das bibliotecas escolares, projeto mobilizador e lei das bibliotecas escolares. In: MORO, E. L. S. et al (Org.). Biblioteca escolar. presente! Porto Alegre: Evangraf/CRB-10, 2011. p. 130-136.

SILVA, W. C. Miséria da biblioteca escolar. São Paulo: Cortez, 1995.

SISTEMA CFB/CRB. Projeto mobilizador: biblioteca escolar construção de uma rede de informação para o ensino público. Brasília: CFB/CRB, 2008. 